Running head: RELATIVE AGE EFFECT IN SHOOTING SPORTS

Is There an Influence of Relative Age on Participation in Non-Physical Sports Activities? The Example of Shooting Sports.

Keywords: Relative Age Effect, Discrimination, Dropout, Shooting sports 


\begin{abstract}
The aim of this study was to test the presence of the Relative Age Effect (RAE) on the overall male $(n=119,715)$ and female $(n=12,823)$ population of the shooting sports federation, and to see if it has an impact on discontinuance. For the boys as for the girls, the results show a uniform distribution of discontinuance. Concerning the girls, a RAE was not found, showing that in female shooting sports this effect is not operating. Looking at the males, a significant statistical RAE was not detected in "18-20 years old" and "13-14 years old" categories. However, this effect was found in "adults", "11-12 years old" and "under 11 years old" categories. A significant "inverse" RAE was found for the "15-17 years old". If the rejection of the null hypothesis in some male age groups of a non-physical sports activity is of interest, further qualitative research is needed in order to clearly understand which factors contribute to this asymmetric distribution of birth dates in French male shooting sports.
\end{abstract}




\section{Is There an Influence of Relative Age on Participation in Non-Physical Sports Activities? The Example of Shooting Sports.}

In competitive sports, players are grouped according to age. The goal of these age categories is to make competition more equal between participants. Despite this, in a system which has the $1^{\text {st }}$ of January as the cut-off date, for example, a child born in January can have an advantage of physical and cognitive maturity of 12 months compared to a child born in December in that same year, although the two will find themselves in the same age group. In terms of relative age, there can be a large difference between the young players in the same age category. This gap is noticeably apparent in terms of physical development (Tanner \& Whitehouse, 1976) and also in cognitive development (Bisanz, Morrison \& Dunn, 1995). This advantage (or disadvantage) of relative age will reach its climax at the point of puberty. Thus, Delorme and Raspaud (2009) have shown that in all French youth basketball age categories, the children born at the beginning of the competitive year (i.e., the oldest relative age) are always significantly taller on average than those born at the end of the year. The greatest difference in average size of the two groups is at the beginning of puberty (La Rochebrochard, 2000), with 4.53 centimetres for the girls at 10 years old, and 5.21 centimetres for the boys at 13 years old. The consequence of relative age is called "Relative Age Effect" (RAE)

Grondin, Deshaies and Nault (1984) were the first to discuss the possible relationship between the trimester of birth and achieving a high sporting level. In analysing the data of the National Hockey League, it reveals an over-representation of players born at the start of the year and a significant under-representation of those born at the end of the year. They 
suggest that this biased distribution was the consequence of the $1^{\text {st }}$ of January cut-off date, which was used to determine the age categories for minor hockey.

Since this first study, an increasing amount of work has been published on RAE in the sporting domain. The research on professional sports mainly focuses on football and ice hockey (Musch \& Grondin, 2001); however, there are also numerous studies of baseball (Thompson, Barnsley \& Stebelsky, 1991; Stanaway \& Hines, 1995), basketball (Daniel \& Janssen, 1987; Côté, Macdonald, Baker \& Abernethy, 2006; Delorme, Boiché \& Raspaud, in press), American football (Daniel \& Janssen, 1987; Stanaway \& Hines, 1995) and tennis (Edgar \& O’Donoghue, 2005). Such investigations are also carried out at the youth level and the youth elite level. Here too, ice hockey and football are most often studied (Musch \& Grondin, 2001). There are also some studies on baseball (Thompson, Barnsley \& Stebelsky, 1992), basketball (Delorme \& Raspaud, 2009), gymnastics (Baxter-Jones, 1995), swimming (Baxter-Jones, 1995), tennis (Dudink, 1994; Edgar \& O’Donoghue, 2005) and volleyball (Grondin et al., 1984).

With a few rare exceptions (Daniel \& Janssen, 1987; Baxter-Jones, 1995; Stanaway \& Hines, 1995; Côté et al., 2006; Delorme et al., in press) most of the studies report a significant RAE, especially in sports where height, weight and strength are considered as assets (Musch \& Grondin, 2001). Activities such as dance and gymnastics, where physical attributes are ineffective, or even disadvantageous, RAE is not present. The work of BaxterJones and Helms (1996) and Malina, Bouchard and Bar-Or (2004) show that late puberty is an advantage for gymnasts and dancers. In addition, it has been observed that a positive correlation exists between late puberty and the practice of gymnastic at a high level (BaxterJones, 1995; Baxter-Jones et al., 1995). For Van Rossum (2006), the presence or absence of RAE is a function of motor skills. Thus, the author argues that a RAE should not be imposed in activities where physicality is not important. 
The unequal distribution of athletes at a professional level is explained by others using a model of selection giving value to premature physical development which leaves sportsmen/women born late in the competitive year behind (Sherar, Baxter-Jones, Faulkner \& Russel1, 2007)._The athletes born early in the competitive year possess significant assets in terms of their development (i.e., size, weight and force) which influence their perceived potential (Helsen, Van Winckel \& Williams, 2005). These adolescents being more easily identified as talented or promising and are thus more easily selected to enter professional team training centres or sports institutes for youth national teams and thus have a greater possibility of a professional career. This early exposure to high level training gives them a decisive advantage in terms of skills and game knowledge (Williams, 2000; Ward \& Williams, 2003). Thus, RAE is considered a discriminatory effect in the junior categories because it disadvantages the players born late after the cut-off date, as it reduces their chances of selection to elite groups (Musch \& Hay, 1999). Given the lucrative nature of certain professional sports, this discrimination requires particular attention.

Parallel to this phenomenon, it can be equally noted that certain activities dissuade the youngest players in relative age from taking up a sport. Indeed, Delorme and Raspaud (2009) report a significant RAE in the entire youth categories of French basketball for girls and boys. Their results show that the children born late in the competitive year suffer from a significant disadvantage in size and as a consequence have a lesser tendency to take up this sport. This explains their systematic under-representation. In addition to this auto-elimination at the entry level, [Authors] note that young players born early in the competitive year are significantly under-represented in the statistics of those who quit basketball, whilst their counterparts born at the end of the year are largely over represented. 
The unequal distribution of the month of birth of high level athletes is explained by the joint action of the two mechanisms described above; on one side, the youngest players participate less and /or discontinue more easily sports which require strong physical attributes, and on the other side, the oldest players enter more easily into elite training programs. These two phenomena (i.e., auto-elimination/discontinuance and recruitment) thus facilitate the entry of children born just after the cut-off-date into a professional sporting career.

Despite the now substantial literature on RAE, Musch and Grondin (2001) observe that the effect of an athlete's gender on this phenomenon still remains neglected in the literature. The rare research carried out has led to contradictory results. Baxter-Jones (1995) studied elite gymnasts in Britain and observed no RAE for girls or boys. Van Rossum (2006) arrived at the same conclusion for professional dancers in the Netherlands. In the same way, Vincent and Glamser's study (2006) compared the RAE of 1344 male and female footballers considered by the US Olympic Development Program. The results reveal a marginal RAE for the girls at a regional and national level and no RAE for those at a state level. However, a strong RAE has been noted for the males at a regional, state and national level. Delorme et al. (2009) also do not find a RAE among high level French female soccer players, basketball players and handball players.

Contrary to these results, Delorme and Raspaud (2009) observed a significant RAE in the entire youth female and male categories in French basketball. This phenomenon is even more pronounced with girls than with boys, despite Musch and Grondin's $(2001,162)$ assertion that "stronger RAEs in male youth sports can be predicted." Indeed, Baxter-Jones (1995) suggested that the stronger RAE among male players is the result of the earlier maturation of girls and the higher variance of the maturity status of boys. During the period 
of selection, there would thus be more important differences between boys than between girls. Vincent and Glamser (2006, p. 412) argued that social pressures to conform to a socially constructed gender role (i.e., stereotyped definition of femininity) 'could make early maturing females less motivated to achieve excellence in competitive sport because of a perception that society does not value female athletic accomplishments in the same way it does those of males'. Shakib (2003) provided an illustration of this phenomenon in her study about female basketball participation, showing that before and after puberty, girls' peer statuses and gender statuses are conflated. Girls have to renegotiate a tension between popularity (i.e., peer status) and athleticism. Thus, early maturing females are more subject to leave competitive sports than later maturing females. The physical advantage provided by an early maturation to excel more early in certain sports would thus be more profitable among boys than among girls.

It is noted that up until present, the entire body of literature on RAE has been carried out on sports where the physical attributes of participants have a decisive advantage either because they are very developed (e.g., ice-hockey, football) or because they are not yet developed (e.g., gymnastics, dance). Thus it seems useful to take interest in a sporting activity in which physical attributes have a priori no impact, in order to observe how RAE functions. Our attention is therefore turned to a non physical discipline: shooting sports. The French Federation for Shooting Sports (FFT) manages ten disciplines covering numerous arms (e.g., pistols, rifles) over numerous distances (i.e., 10 to 300 metres). Within these disciplines, there are eight events which are in the males' Olympic program and seven events for the women's Olympic program.

Due to the fact that the morphological and muscular characteristics of children do not allow them to hold classic arms, intended for adults, the FFT has incited the fabrication of 
adapted arms, which use compressed carbon dioxide. These adapted arms are also smaller, lighter and offer greater manoeuvrability. The FFT has also put in place a progression system, allowing the children to use adjustable aids, in function with their age and level. Thus even in the youth categories, the differences in physical development due to relative age remain ineffective.

The study will examine the entire membership body of the federation during the 20062007 season, which will allow a diachronic analysis of this phenomenon. In light of the contradictory results obtained concerning the sex of athletes and RAE, women and men will be separated to assess if there is an impact on the RAE. We will also focus on the members of the 2006-2007 season who did not renew their memberships for the 2007-2008 season; thus we will observe whether RAE affects discontinuance of membership, just as [Authors] suggest.

Given that it concerns an activity in which physical attributes are not operating, the hypothesis is that there will be an absence of RAE for girls and for boys, in youth and adult categories. For the same reasons, it can be hypothesised that a uniform distribution of those discontinuing the sport across all categories for girls and boys will be seen.

\section{Methodology}

\section{Data Collection}

For the needs of this current study, the dates of birth of the entire membership body, will be taken from the FFT database for girls $(n=12,823)$ and boys $(n=119,715)$. The federation has also given the dates of birth of those who did not renew their memberships for the 2007-2008 season. We also waited for the end of the 2007-2008 season to ensure that 
some members had not renewed their license later during the year. The identification of people who discontinued this sport can be identified by the fact that the FFT attributes a lifelong number to members.

At the youth level, the FFT has five different age categories: "under 11 years old", "11-12 years old", "13-14 years old", "15-16 years old" and "18-20 years old". The cut-off date used to determine the categories is the $1^{\text {st }}$ January. The FFT competition year cut-off date is the same as the French school year one. Furthermore, shooting sports are not a discipline included in the French physical education programs. Thus, given that there are not inconsistencies in school and competition cut-off dates, the present RAE study results cannot be confounded (see O'Donoghue, Edgar \& McLaughlin, 2004).

\section{Data Analysis}

In the current literature, the presence of RAE is determined by testing if a significant statistical difference exists between the expected number of players born per month or per quarter (i.e., three consecutive months) and the observed number. In relation to FFT, the cutoff date is $1^{\text {st }}$ January. Thus, the birth month of members are classed in four quarters, starting with the period January-March (Q1) and ending with the period October-December (Q4). Next, a chi-square test is used to determine if the observed distribution differs significantly from the expected distribution. Similar to previous works, the expected distribution is calculated from statistics of the distribution of birth months, by gender and by year, for the national population, using weighted means. These data have been obtained from the National Institute of Statistics and Economic Studies.

As pointed by Musch and Hay (1999) a chi-square test cannot shed light on the existence of trends in the data. Consequently, for each significant chi-square test, the predicted linear relationship between month of the competition year and the distribution of 
members was examined by calculating the Kendall tau rank correlation coefficient between the month of the competition year and the difference between the expected and observed number of members for each month. These tests were conducted one-tailed according to the direction of the investigated effect. Consequently, a negative sign of the correlation will indicate that members born at the beginning of the competition year are overrepresented.

In relation to discontinuance, the expected distribution is calculated from the statistics of birth month, by gender and by year for the population of FFT members, using weighted means. For this type of analysis, it is more precise to take the statistics of all the members as the expected distribution, rather than the national population statistics (Delorme \& Raspaud, 2009).

\section{Results}

Tables 1 and 2 respectively present the distribution per quarter and per category of boy and girl members during 2006-2007 season.

**** Table 1 near here $* * * *$

$* * * *$ Table 2 near here $* * * *$

Concerning the females, a significant statistical RAE is not found, for the "adults", for the "18-20 years old", for the "13-14 years old", for the "11-12 years old" or for the "under 11 years old". In contrast, a significant biased distribution can be observed for the "15-17 years old" with an over-representation of members in Q1 and an under-representation in the other quarters. 
Looking at the males, a significant statistical RAE is not detected in the " $18-20$ years old" and in the "13-14 years old". However, conforming to the RAE theory, there is a strong over-representation of members in Q1 and a strong under-representation in Q3 and Q4 for the "adults" $(\tau=-.39, p<.05)$, the "11-12 years old" $(\tau=-.36, p<.05)$ and the "under 11 years old" $(\tau=-.67, p<.01)$. Finally a significant "inverse" RAE is found for the " $15-17$ years old" $(\tau=.36, \mathrm{p}<.05)$, with an over-representation in $\mathrm{Q} 4$ and an under-representation in the other quarters.

Table 3 presents the percentages of those discontinuing, by age category and by sex, for the 2006-2007 season.

**** Table 3 near here $* * * *$

For all the youth boy and girl categories, it can be stated that there is a high level of discontinuance during or at the end of the season studied. The rate of discontinuing however, is higher amongst the girls than the boys. For females, the age categories " $15-17$ years old" and "18-20 years old" have the highest level of discontinuance. For males, the highest levels of discontinuance are seen in the "11-12 years old", "13-14 years old" and "15-17 years old" categories. For the two sexes, it is noted that in the "adults" are least likely to discontinue, with a rate nevertheless higher for women than for men.

Tables 4 and 5 respectively present the distribution per quarter and by age category for girls and boys discontinuing during the 2006-2007 season. 
$* * * *$ Table 4 near here $* * * *$

$* * * *$ Table 5 near here $* * * *$

Concerning the girls discontinuing, a statistically biased distribution is not found in "adults", nor in "18-20 years old", nor in "15-17 years old", nor in "13-14 years old", nor in "11-12 years old" and nor in "under 11 years old".

The distribution is uniform for the males, just like their female counterparts, in every age categories.

\section{Discussion}

Since the body of research on RAE concerns sports in which physical attributes have a significant impact on performance, we turn our attention to a discipline in which these attributes seem a priori to be inoperative; thus we aim to test the presence of this effect on participation and abandonment. Given that shooting sports are non physical, we hypothesize that there will be an absence of RAE and that there will be consistent discontinuance for boys and for girls, and in all age categories.

In relation to the girls, a biased distribution is not found, except for the "15-17 years". Despite this, this distribution does not correspond with the usual distribution observed in cases where RAE operates: there is an over-representation in Q1, yet an under-representation is not noted in Q4. While, in the RAE theory, an over-representation in the first six months of the year and an under-representation in the last six months is generally seen (Musch \& Grondin, 2001). A new analysis was then carried out, by grouping together Q1 with Q2 and Q3 with Q4, however, this analysis still did not show a significant $\operatorname{RAE}\left(\chi^{2}=1.128\right.$, d.f. $=1$, 
$P<0.288$ ). It can therefore be concluded that RAE is not found in French female shooting sports, conforming to our initial hypothesis.

In the category of women discontinuing, it is noted that for all the age categories, the distribution observed does not differ from that of the expected distribution. Contrary to French female youth basketball study by [Authors], an over-representation of girls born in Q4 discontinuing this sport is not noticed, nor an under-representation of those born in Q1.

These results support our initial hypothesis that in female shooting sports, a difference in terms of relative age is not operating. Auto-elimination at the entry level of those born in Q4, as described by Delorme and Raspaud (2009) is not found. Neither is the overrepresentation of discontinuance seen by those same individuals. Thus, in relation to females, this study confirms the proposition of Van Rossum (2006), that is to say, that the presence or absence of RAE seems tied to the motor skill characteristics. In the case of non-physical sports, the differences in physical and cognitive development of participants, do not come into play.

For the boys, the initial hypothesis of an absence of RAE in all age categories has not been verified. Numerous scenarios in function with the age of members can be distinguished.

First of all, it is noticed that a significant statistical RAE exists in the "under 11 years old" and "11-12 years old" categories. This asymmetrical distribution is not due to discontinuance, as there is uniform distribution across the two age categories. The unevenness of the distribution of members therefore comes from a stronger recruitment of young boys born in Q1, whilst those born in Q3 and Q4 are less likely to get involved in this sport. Given the young age of children, it is reasonable to think that becoming involved in this discipline is decided primarily by parental authorisation. As noted in the introduction, children born in Q3 and in Q4 are less physically and cognitively developed than are their 
counterparts born in Q1. Taking note of the social representations of danger and associated violence of firearms and their utilisation, it can be thought, that parents may have less hesitation to authorise their children participating in this sport, if they are among the older children in their age groups. This reasoning can therefore explain the asymmetry observed. The work carried out on RAE in the scholarly domain, shows that the children having the youngest relative age (i.e., those born late in relation to the cut-off date) are more likely to fail (e.g., Diamond, 1983) and succeed significantly less than the students born just after the cut-off date (e.g., Davis, Trimble \& Vincent, 1980; Uphoff \& Gilmore, 1986; Sweetland \& De Simone, 1987). Perhaps this scholarly success contributes to the child projecting a 'serious' essence which facilitates parental agreement. The diachronical evolution of distribution seems to support this interpretation; the strongest RAE is observed amongst the "under 11 years old", then decreases in "11-12 years old" and finally disappears in "13-14 years old". Nevertheless, we must remain careful with this interpretation. A qualitative study about young members' parents is needed in order to clearly determine which reasons/factors led them to allow their children to practice this sport.

Secondly, a significant statistical "inverse" RAE appears amongst the " $15-17$ years old", whilst there is a uniform distribution of birth dates for the "13-14 years old". Thus, an over-representation of those born in Q4 and an under-representation of those born in Q1 is noted. This asymmetry is not a result of discontinuance, as the results are distributed in a uniform manner across the quarters. The "inverse" RAE observed here is therefore the result of a greater participation in this activity by children born in Q4 than those born in Q1. This phenomenon could be explained by weak players who changed sports after failing in disciplines in which developed physical attributes are determinant. Indeed, Delorme and Raspaud (2009) reveal that within French basketball, it is in the "13-14 years old" category where the greatest difference in size is found. Thus, the players born in Q1 are on average 
4.88 centimetres taller than their team-mates born in Q4. It is also amongst the basketball players in the "13-14 years old" category, where [Authors] find the greatest overrepresentation of those discontinuing (in Q4), whereas those born in Q1 are clearly underrepresented. The basketball players born in Q4 exhibit less physical maturity on average, and thus have a greater tendency to discontinue this activity. It is therefore reasonable to venture that they enrol in sporting activities in which physical attributes are inconsequential. Therefore, this could explain the over-representation noted in Q4. Even if the work of Delorme and Raspaud (2009) and [Authors], supports this interpretation, we must remain careful. Only a qualitative analysis carried out concerning the new members of this age category, would confirm the reality of this transfer.

Finally, in the "adults" category, our initial hypothesis has not been verified, given the presence of a significant RAE in the results. Indeed, as there is an over-representation of members in Q1 and an under-representation of members in other quarters, this distribution is typical of RAE, given that in grouping together Q1 with Q2 and Q3 with Q4, this allows an over-representation amongst the first group to appear, and under-representation amongst the second group, which is statistically significant $\left(\chi^{2}=5.796\right.$, d.f. $\left.=1, P<0.016\right)$. The overrepresentation of members in Q1 is not explained by discontinuance, as these are distributed in a uniform manner across the different quarters. This asymmetry could be explained by a transfer of sportsmen born in Q1 who find themselves in the situation of failure in the sports privileging developed physical attributes. In fact, in Bäumler's study (1996) carried out on the Germany Professional Football Championships, the author has shown a negative correlation between age and RAE; the more the age increases, the more RAE declines. Thus the author notes that amongst the " $18-22$ years old", $68 \%$ of players are born in the first six months of the competitive year. This proportion will diminish continually until reaching a uniform distribution at "33-35 years old". Bäumler (1996) concludes that the physical 
advantage of players born in Q1 and Q2 is reduced with time and that the reduction of RAE corresponds to a shift in direction of players possessing the best technical attributes, who have suffered from disadvantages in terms of relative age in their youth. The recent work of Ashworth and Heyndels (2007) confirms this analysis. Basing their research on the German Football Championships, they find a significant RAE. However, they note that although being underrepresented, the players born in Q3 and Q4 are more competitive and reach a better salary than their team-mates born just after the cut-off date. The authors put forward two explanations for this phenomenon. Firstly they suggest that players born late after the cut-off date, who are still participating in the sport, have survived the recruitment process which normally discriminates against them. For the authors, "to succeed in such survival is possible only if they are of above-average talent" (p. 372). Secondly, they suggest that the players born in the second half of the year have benefited from a greater quantity of training due to the systematic confrontation with their counterparts with more developed physical attributes. In fact, "the age grouping creates a systematic advantage for late-born players who receive their soccer education together with players who, though equally talented, are better than themselves (just because they are a few months older)" (p. 372). Thus, the adults born in Q1, who find themselves failing, as a result of the progressive reduction of the initial disadvantage due to relative age of their counterparts born in Q4, could thus lead them to switch to sports where physical attributes are not operating. Once again, we must be careful with this interpretation, which must be supported by a qualitative study about the new adult members of the FFT with the goal of drawing up a history of their old sporting practices, to determine the reasons of their new participation in this activity.

\section{Conclusion}


For Van Rossum (2006), the presence or absence of RAE is a function of motor skills. Thus, the author argues that a RAE should not be imposed in activities where physicality is not important. While our results about French female shooting sports confirm this hypothesis, the results of the male shooting sports make it invalid. Indeed, although male sport shooting seems to be a discipline where physical attributes do not play a priori a determining role in the decision to participate or discontinue this activity, our results suggest that some exogenous factors deriving from relative age (e.g., parental authorisation, failure in another sport) might explain the biased distribution in some age groups.

However that may be, we must remain very careful with the varied proposed interpretations. Indeed, if the rejection of the null hypothesis in some male age groups of a non-physical sports activity is of interest, further qualitative research is needed in order to clearly understand which factors contribute to this asymmetric distribution of birth dates in French male shooting sports. 


\section{References}

Ashworth, J. \& Heyndels, B. (2007). Selection bias and peer effects in team sports: The effect of age grouping on earnings of German soccer players. Journal of Sports Economics, 8 , $355-377$.

Bäumler, G. (1996). The relative age effect in soccer and its interaction with chronological age. Talk at the Soccer Sport Science Symposium in Oberhaching, September 1996.

Baxter-Jones, A. (1995). Growth and development of young athletes. Should competition levels be age related? Sports Medicine, 20, 59-64.

Baxter-Jones, A. \& Helms, P. (1996). Effects of training at young age: a review of the Training of Young Athletes (TOYA) study. Pediatrics Exercise Science, 8, 310-327.

Baxter-Jones, A., Helms, P., Maffull, N., Baines-Preece, J. \& Preece, M. (1995). Growth and development of male gymnasts, swimmers, soccer and tennis players: A longitudinal study. Annals of Human Biology, 22, 381-394.

Bisanz, J., Morrison, F. \& Dunn, M. (1995). Effects of age and schooling on the acquisition of elementary quantitative skills. Developmental Psychology, 31, 221-236.

Côté, J., Macdonald, D. J., Baker, J. \& Abernethy, B. (2006). When “where”' is more important than "when": Birthplace and birthdate effects on achievement of sporting expertise. Journal of Sports Sciences, 24, 1065-1073.

Daniel, T. E. \& Janssen, C. T. L. (1987). More on the relative age effect. Canadian Association for Health, Physical Education and Recreation, 53, 21-24.

Davis, B. D., Trimble, C. S. \& Vincent, D. R. (1980). Does age of entrance affect school achievement? The Elementary School Journal, 80, 133-143.

Delorme, N., Boiché, J. \& Raspaud, M. (2009). The relative age effect in elite sport: the French case. Research Quarterly for Exercise and Sport, 80, 336-344. 
Delorme, N. \& Raspaud, M. (2009). The relative age effect in young French basketball players: a study on the whole population. Scandinavian Journal of Medicine \& Science in Sports, 19, 235-242.

Diamond, G. H. (1983). The birthdate effect - A maturational effect? Journal of Learning Disabilities, 16, 161-164.

Dudink, A. (1994). Birth date and sporting success. Nature, 368, 592.

Edgar, S. \& O’Donoghue, P. (2005). Season of birth distribution of elite tennis players. Journal of Sports Sciences, 23, 1013-1020.

Grondin, S., Deshaies, P. \& Nault, L. P. (1984). Trimestres de naissance et participation au hockey et au volleyball. La Revue Québécoise de l'Activité Physique, 2, 97-103.

Helsen, W. F., Van Winckel, J. \& Williams, A. M. (2005). The relative age effect in youth soccer across Europe. Journal of Sports Sciences, 23, 629-636.

La Rochebrochard, E. (2000). Age at puberty of girls and boys in France: measurements from a survey on adolescent sexuality. Population: An English Selection, 12, 51-79.

Malina, R. M., Bouchard, C. \& Bar-Or, O. (2004). Growth, maturation and physical activity. Champaign, IL: Human Kinetics.

Musch, J. \& Grondin, S. (2001). Unequal competition as an impediment to personal development: A review of the Relative Age Effect in Sport. Developmental Review, 21, $147-167$

Musch, J. \& Hay, R. (1999). The relative age effect in soccer: Cross-cultural evidence for a systematic discrimination against children born late in the competition year. Sociology of Sport Journal, 16, 54-64.

O'Donoghue, P., Edgar, S. \& McLaughlin, E. (2004). Season of birth in elite cricket and netball. Journal of Sports Sciences, 22, 256-257. 
Shakib, S. (2003). Female basketball participation. Negotiating the conflation of peer status and gender status from childhood through puberty. American Behavioural Scientist, 46, $1405-1422$.

Sherar, L. B., Baxter-Jones, A. D., Faulkner, R. A. \& Russell, K. W. (2007). Do physical maturity and birth date predict talent in male youth ice hockey players? Journal of Sports Sciences, 25, 879-886.

Stanaway, K. B. \& Hines, T. (1995). Lack of a season of birth effect among American athletes. Perceptual and Motor Skills, 81, 952-954.

Sweetland, J. D. \& De Simone, P. A. (1987). Age of entry, sex, and academic achievement in elementary school children. Psychology in the Schools, 24, 406-412.

Tanner, J. M. \& Whitehouse, R. H. (1976). Clinical longitudinal standards for height, weight, height velocity and weight velocity and the stages of puberty. Archives of Disease in Childhood, 51, 170-178.

Thompson, A., Barnsley, R. \& Stebelsky, G. (1991). 'Born to play ball': The relative age effect and major league baseball. Sociology of Sport Journal, 8, 146-151.

Thompson, A., Barnsley, R. \& Stebelsky, G. (1992). Baseball performance and the relative age effect: Does little league neutralize birthdate selection bias? Nine, 1, 19-30.

Uphoff, J. K. \& Gilmore, J. (1986). Pupil age at school entrance - How many are ready for success? Young Children, 41, 11-16.

Van Rossum, J. H. A. (2006). Relative age effect revisited: findings from the dance domain. Perceptual and Motor Skills, 102, 302-308.

Vincent, J. \& Glamser, F. D. (2006). Gender differences in the relative age effect among US Olympic Development Program youth soccer players. Journal of Sports Sciences, 24, 405-414 
Ward, P. \& Williams, A. M. (2003). Perceptual and cognitive skill development in soccer: The multidimensional nature of expert performance. Journal of Sport and Exercise Psychology, 25, 93-111.

Williams, A. M. (2000). Perceptual skill in soccer: Implications for talent identification and development. Journal of Sports Sciences, 18, 737-740. 
Table 1. Distribution of female license holders (2006-2007).

\begin{tabular}{|c|c|c|c|c|c|c|c|}
\hline & $\begin{array}{c}\mathbf{Q} 1(\%) \\
\text { (expected) }\end{array}$ & $\begin{array}{c}\text { Q2 }(\%) \\
\text { (expected) }\end{array}$ & $\begin{array}{c}\text { Q3 }(\%) \\
\text { (expected) }\end{array}$ & $\begin{array}{c}\mathbf{Q} 4(\%) \\
\text { (expected) }\end{array}$ & Total & $\chi^{2}$ & $P$ \\
\hline Adults & $\begin{array}{c}2,498(24.56) \\
(2,498)\end{array}$ & $\begin{array}{c}2,674(26.29) \\
(2,673)\end{array}$ & $\begin{array}{c}2,606(25.62) \\
(2,565)\end{array}$ & $\begin{array}{c}2,393(23.53) \\
(2,435)\end{array}$ & 10,171 & 1.399 & 0.706 \\
\hline $18-20$ & $\begin{array}{c}156(26.71) \\
(141)\end{array}$ & $\begin{array}{c}146(25.00) \\
(151)\end{array}$ & $\begin{array}{c}145(24.83) \\
(148)\end{array}$ & $\begin{array}{c}137(23.46) \\
(144)\end{array}$ & 584 & 2.231 & 0.526 \\
\hline $15-17$ & $\begin{array}{c}227(28.44) \\
(193)\end{array}$ & $\begin{array}{c}184(23.06) \\
(203)\end{array}$ & $\begin{array}{c}192(24.06) \\
(206)\end{array}$ & $\begin{array}{c}195(24.44) \\
(196)\end{array}$ & 798 & 8.501 & 0.037 \\
\hline $13-14$ & $\begin{array}{c}128(25.10) \\
(121)\end{array}$ & $\begin{array}{c}136(26.67) \\
(130)\end{array}$ & $\begin{array}{c}124(24.31) \\
(132)\end{array}$ & $\begin{array}{c}122(23.92) \\
(127)\end{array}$ & 510 & 1.256 & 0.739 \\
\hline $11-12$ & $\begin{array}{c}118(24.79) \\
(113)\end{array}$ & $\begin{array}{c}119(25.00) \\
(120)\end{array}$ & $\begin{array}{c}120(25.21) \\
(123)\end{array}$ & $\begin{array}{c}119(25.00) \\
(120)\end{array}$ & 476 & 0.268 & 0.966 \\
\hline$<11$ & $\begin{array}{c}72(25.35) \\
(68)\end{array}$ & $\begin{array}{c}79(27.82) \\
(72)\end{array}$ & $\begin{array}{c}68(23.94) \\
(73)\end{array}$ & $\begin{array}{c}65(22.89) \\
(71)\end{array}$ & 284 & 1.737 & 0.629 \\
\hline TOTAL & $\begin{array}{c}3,199(24.95) \\
(3,149\end{array}$ & $\begin{array}{c}3,338(26.03) \\
(3,370)\end{array}$ & $\begin{array}{c}3,255(25.38) \\
(3,234)\end{array}$ & $\begin{array}{c}3,031(23.64) \\
(3,070)\end{array}$ & 12,823 & 1.738 & 0.628 \\
\hline
\end{tabular}


Table 2. Distribution of male license holders (2006-2007).

\begin{tabular}{|c|c|c|c|c|c|c|c|}
\hline & $\begin{array}{c}\text { Q1 (\%) } \\
\text { (expected) }\end{array}$ & $\begin{array}{c}\text { Q2 (\%) } \\
\text { (expected) }\end{array}$ & $\begin{array}{c}\text { Q3 (\%) } \\
\text { (expected) }\end{array}$ & $\begin{array}{c}\text { Q4 (\%) } \\
\text { (expected) }\end{array}$ & Total & $\chi^{2}$ & $P$ \\
\hline Adults & $\begin{array}{c}27,107(25.04) \\
(26587)\end{array}$ & $\begin{array}{c}28,328(26.17) \\
(28452)\end{array}$ & $\begin{array}{c}26,938(24.88) \\
(27298)\end{array}$ & $\begin{array}{c}25,884(23.91) \\
25920\end{array}$ & 108,257 & 15.490 & 0.002 \\
\hline $18-20$ & $\begin{array}{c}440(22.86) \\
(464)\end{array}$ & $\begin{array}{c}523(27.17) \\
(499)\end{array}$ & $\begin{array}{c}472(24.52) \\
(489)\end{array}$ & $\begin{array}{c}490(25.45) \\
(473)\end{array}$ & 1,925 & 3.544 & 0.315 \\
\hline $15-17$ & $\begin{array}{c}744(22.99) \\
(784)\end{array}$ & $\begin{array}{c}818(25.28) \\
(822)\end{array}$ & $\begin{array}{c}797(24.63) \\
(833)\end{array}$ & $\begin{array}{c}877(27.10) \\
(797)\end{array}$ & 3,236 & 11.768 & 0.008 \\
\hline $13-14$ & $\begin{array}{c}627(22.61) \\
(660)\end{array}$ & $\begin{array}{c}738(26.61) \\
(707)\end{array}$ & $\begin{array}{c}699(25.21) \\
(715)\end{array}$ & $\begin{array}{c}709(25.57) \\
(691)\end{array}$ & 2,773 & 3.756 & 0.289 \\
\hline $11-12$ & $\begin{array}{c}587(26.69) \\
(524)\end{array}$ & $\begin{array}{c}557(25.33) \\
(553)\end{array}$ & $\begin{array}{c}517(23.51) \\
(568)\end{array}$ & $\begin{array}{c}538(24.47) \\
(554)\end{array}$ & 2,199 & 12.644 & 0.005 \\
\hline$<11$ & $\begin{array}{c}378(28.53) \\
(318)\end{array}$ & $\begin{array}{c}362(27.32) \\
(336)\end{array}$ & $\begin{array}{c}321(24.23) \\
(341)\end{array}$ & $\begin{array}{c}264(19.92) \\
(330)\end{array}$ & 1,325 & 27.748 & $<0.0001$ \\
\hline TOTAL & $\begin{array}{c}29,883(24.96) \\
(29,401)\end{array}$ & $\begin{array}{c}31,326(26.17) \\
(31,464)\end{array}$ & $\begin{array}{c}29,744(24.85) \\
(30,187)\end{array}$ & $\begin{array}{c}28,762(24.02) \\
(28,663)\end{array}$ & 119,715 & 15.331 & 0.01 \\
\hline
\end{tabular}


Table 3. Discontinuance during 2006-2007 season .

\begin{tabular}{|c|c|c|c|c|c|c|}
\hline & \multicolumn{3}{|c|}{ Females } & \multicolumn{3}{|c|}{ Males } \\
\hline & Total & Dropouts & $\%$ & Total & Dropouts & $\%$ \\
\hline Adults & 10,171 & 2,729 & 26.83 & 108,257 & 19,501 & 18.01 \\
\hline $18-20$ & 584 & 282 & 48.29 & 1,925 & 919 & 47.74 \\
\hline $15-17$ & 798 & 369 & 46.24 & 3,236 & 1,775 & 54.85 \\
\hline $13-14$ & 510 & 206 & 40.39 & 2,773 & 1,518 & 54.74 \\
\hline $11-12$ & 476 & 190 & 39.92 & 2,199 & 1,195 & 54.34 \\
\hline$<11$ & 284 & 112 & 39.44 & 1,325 & 637 & 48.08 \\
\hline Total & 12,823 & 3,888 & 30.32 & 119,715 & 25,545 & 21.34 \\
\hline
\end{tabular}


Table 4. Distribution of discontinuance for females (2006-2007).

\begin{tabular}{|c|c|c|c|c|c|c|c|}
\hline & $\begin{array}{l}\text { Q1 } \\
(\Delta)\end{array}$ & $\begin{array}{l}\text { Q2 } \\
(\Delta)\end{array}$ & $\begin{array}{l}\text { Q3 } \\
(\Delta)\end{array}$ & $\begin{array}{l}\text { Q4 } \\
(\Delta)\end{array}$ & Total & $x^{2}$ & $P$ \\
\hline Adults & $\begin{array}{c}655 \\
(-15)\end{array}$ & $\begin{array}{l}711 \\
(-7)\end{array}$ & $\begin{array}{c}683 \\
(-16)\end{array}$ & $\begin{array}{c}680 \\
(+38)\end{array}$ & 2,729 & 3.012 & 0.390 \\
\hline $18-20$ & $\begin{array}{c}75 \\
(-1)\end{array}$ & $\begin{array}{c}74 \\
(+4)\end{array}$ & $\begin{array}{c}77 \\
(+7)\end{array}$ & $\begin{array}{c}56 \\
(-10)\end{array}$ & 282 & 2.430 & 0.488 \\
\hline $15-17$ & $\begin{array}{c}113 \\
(+8)\end{array}$ & $\begin{array}{c}79 \\
(-6)\end{array}$ & $\begin{array}{c}82 \\
(-7)\end{array}$ & $\begin{array}{c}95 \\
(+5)\end{array}$ & 369 & 1.830 & 0.608 \\
\hline $13-14$ & $\begin{array}{c}51 \\
(-1)\end{array}$ & $\begin{array}{c}51 \\
(-4)\end{array}$ & $\begin{array}{c}59 \\
(+9)\end{array}$ & $\begin{array}{c}45 \\
(-4)\end{array}$ & 206 & 2.252 & 0.522 \\
\hline $11-12$ & $\begin{array}{c}42 \\
(-6)\end{array}$ & $\begin{array}{l}47 \\
(0)\end{array}$ & $\begin{array}{c}54 \\
(+6)\end{array}$ & $\begin{array}{l}47 \\
(0)\end{array}$ & 190 & 1.340 & 0.720 \\
\hline$<11$ & $\begin{array}{l}28 \\
(0)\end{array}$ & $\begin{array}{c}37 \\
(+6)\end{array}$ & $\begin{array}{c}25 \\
(-2)\end{array}$ & $\begin{array}{c}22 \\
(-4)\end{array}$ & 112 & 1.739 & 0.628 \\
\hline
\end{tabular}

Note : $\Delta$ is the difference between observed distribution and theoretical expected distribution. 
Table 5. Distribution of discontinuance for males (2006-2007).

\begin{tabular}{|c|c|c|c|c|c|c|c|}
\hline & $\begin{array}{l}\text { Q1 } \\
(\Delta)\end{array}$ & $\begin{array}{l}\text { Q2 } \\
(\Delta)\end{array}$ & $\begin{array}{l}\text { Q3 } \\
(\Delta)\end{array}$ & $\begin{array}{l}\text { Q4 } \\
(\Delta)\end{array}$ & Total & $x^{2}$ & $P$ \\
\hline Adults & $\begin{array}{l}4,900 \\
(+17)\end{array}$ & $\begin{array}{l}\mathbf{5}, 184 \\
(+81)\end{array}$ & $\begin{array}{l}4,808 \\
(-44)\end{array}$ & $\begin{array}{l}4,609 \\
(-54)\end{array}$ & 19,501 & 2.346 & 0.504 \\
\hline $18-20$ & $\begin{array}{l}207 \\
(-3)\end{array}$ & $\begin{array}{c}225 \\
(-25)\end{array}$ & $\begin{array}{c}238 \\
(+13)\end{array}$ & $\begin{array}{c}249 \\
(+15)\end{array}$ & 919 & 4.175 & 0.243 \\
\hline $15-17$ & $\begin{array}{l}400 \\
(-8)\end{array}$ & $\begin{array}{l}442 \\
(-7)\end{array}$ & $\begin{array}{c}442 \\
(+5)\end{array}$ & $\begin{array}{c}491 \\
(+10)\end{array}$ & 1,775 & 0.520 & 0.914 \\
\hline $13-14$ & $\begin{array}{c}326 \\
(-18)\end{array}$ & $\begin{array}{c}407 \\
(+3)\end{array}$ & $\begin{array}{c}383 \\
(+1)\end{array}$ & $\begin{array}{c}402 \\
(+14)\end{array}$ & 1,518 & 1.381 & 0.710 \\
\hline $11-12$ & $\begin{array}{l}311 \\
(-8)\end{array}$ & $\begin{array}{l}302 \\
(-1)\end{array}$ & $\begin{array}{l}278 \\
(-3)\end{array}$ & $\begin{array}{c}304 \\
(+12)\end{array}$ & 1,195 & 0.690 & 0.876 \\
\hline$<11$ & $\begin{array}{c}184 \\
(+3)\end{array}$ & $\begin{array}{c}174 \\
(0)\end{array}$ & $\begin{array}{r}148 \\
(-7)\end{array}$ & $\begin{array}{c}131 \\
(+4)\end{array}$ & 637 & 0.470 & 0.925 \\
\hline
\end{tabular}

Note : $\Delta$ is the difference between observed distribution and theoretical expected distribution. 